\title{
Physical properties and cooking quality of extruded restructured rice: impact of water temperature and water level
}

\author{
${ }^{1,2}$ Patria, D.G., ${ }^{2}$ Sutrisno, A., ${ }^{1}$ Hsu, J.-L. and ${ }^{3 *}$ Lin, J. \\ ${ }^{1}$ Department of Biological Science and Technology, National Pingtung University of Science and \\ Technology, Pingtung, 91201 Taiwan \\ ${ }^{2}$ Department of Agricultural Product Technology, University of Brawijaya, Malang, 65145 Indonesia \\ ${ }^{3}$ Department of Food Science, National Pingtung University of Science and Technology, Pingtung, 91201 \\ Taiwan
}

\section{Article history: \\ Received: 30 March 2020 \\ Received in revised form: 20 \\ April 2020 \\ Accepted: 23 April 2020 \\ Available Online: 5 June \\ 2020}

\section{Keywords:}

Extrusion,

Surface,

Pasta extruder,

Restructured rice

\section{DOI:}

https://doi.org/10.26656/fr.2017.4(5).141

\begin{abstract}
Rice is the main food for approximately 3.5 billion people worldwide, especially in Asians, who have consumed more than $90 \%$ of the total rice produced. Restructured rice is another designation of artificial rice is an effort to diversify staple foods processed from carbohydrate-based raw materials with the addition of certain substances to improve the quality of staple foods. Restructured rice can be done with several techniques, such as using extrusion. This study aimed to investigate the effect water content $(35 \%, 37.5 \%$, $40 \%, 42.5 \%$, and $45 \%)$ and temperature $\left(100^{\circ} \mathrm{C}\right.$ and $\left.26^{\circ} \mathrm{C}\right)$ on the surface and characteristics of restructured rice using a pasta extruder. Results of this study showed the treatment with water content $40 \%$ and temperature $100^{\circ} \mathrm{C}$ to be the best, more precisely seen from the results of laser microscope, color, WAI, WSI, WAR, Cooking losses, and cooking time. Pores and surfaces of restructured rice are almost the same as milled rice. Water absorption index (WAI) value $=2.273 \pm 0.10 \mathrm{~g} / \mathrm{g}$, WSI $=2.114 \pm 0.11 \%$, WAR $=$ $150.99 \pm 0.77 \%, C L=1.92 \pm 0.10 \%$ and cooking time 4 mins. Suggestions for this research are further studies such as fortification with other ingredients using a pasta extruder technology and are expected to be implemented and commercialized.
\end{abstract}

\section{Introduction}

Rice (Oryza sativa L.) is one of the most widely produced and consumed grains in the world because it is the main food source for more than half the world's population. Rice is also an important source of energy for human consumption because it has a high content of starch and a source of minerals, protein, and vitamins (Walter et al., 2005). Rice is the main food for approximately 3.5 billion people in the world, especially to Asians, who have consumed more than $90 \%$ of the total rice produced (Mohanty, 2013). Rice has specific characteristics, such as hypoallergenic, ability to bring flavor and taste, making it the desired seed for use in value-added products. Some examples of these products include tortillas, gluten-free rice bread, drinks, low-fat sauces, processed meats, puddings, salad dressings, and artificial rice. Changing rice flour can change its functional properties in such a way that it can be used as a substitute for products that have other added values (Wang et al., 2013).
Restructured rice is another designation of artificial rice is an effort to diversify staple foods processed from carbohydrate-based raw materials with the addition of certain substances to improve the quality of staple foods, so that can be used as food functional. Restructured rice can be done with several techniques, such as using extrusion. According to Mishra et al. (2012) extrusion technology can be classified into two categories: hot extrusion and cold extrusion. Both processes have a dough shaped material made from the main components (mostly rice flour), additive mixtures, and water through single or twin-screw extruders, while Alavi et al. (2008) reported does not utilize any additional thermal energy input other than the heat generated during the process itself, and is primarily a low temperature (below $70^{\circ} \mathrm{C}$ ), forming process resulting in grains that are uncooked, opaque, and easier to differentiate from regular rice kernels. Much research on rice production was restructured using cooking/hot extruders. This research to study about the production of restructured rice using a pasta extruder because it is easier to operate and simpler 
to produce than cooking extruder, but the problem is to know how much composition is right to produce good restructured rice because pasta extruder does not use heat energy in the process.

Many studies on cooking extrusion have extrusion effects on the quality parameters of extruded products (Dalbhagat and Mishra, 2019), texture evaluation of extruded rice (Wang et al., 2013), micronutrient stability (Dalbhagat and Mishra, 2019), and cooking characteristics in food extrusion (Singh et al., 2005) have been reported. However, this review brings together recent research on extruded rice and rice-based products and the effects of water content and temperature parameters using a pasta extruder.

Research about the effect of water content and temperature on production of restructured rice using pasta extruder has never been done. So, it is necessary to research to obtain an appropriate formulation in the use of the water content and temperature to produce restructured rice with good physical, chemical, and cooking characteristics. This study is used to prepare the restructured rice that will be fortified with other ingredients using a pasta extrusion technology. Various ingredients are added to rice flour to improve the nutritional, texture or sensory attributes of rice-based extrudates. To improve texture, rheology and functional properties and to reduce the loss of cooking the final product, proteins such as egg white powder, lupine, casein, etc. Added as a structuring agent (Dalbhagat and Mishra, 2019).

\section{Materials and methods}

\subsection{Materials}

White Rice Japonica Tainan 11: TN-11 (ShuenBau Factory, Pingtung, Taiwan) as the main material. Calcium Hydroxide (Showa Chemical Co. Ltd., Japan), Xanthan Gum (Gemfon Corporation, Taiwan), Emulsifier (Sin Shen Cheng Factory, Taiwan), Shortening (Wang Lai Store, Pingtung, Taiwan).

\subsection{Preparation of rice flours}

Japonica rice (Oryza sativa) variety Tainan 11: TN11 was grounded using small grinder (RT-04, Mill Powder Tech Co., Ltd., Taiwan), and sieved through an 80-mesh using sieve shakers (AS 200, RETSCH Ltd., Germany), test sieve no 80 Mesh (Standard ASTM E1109 RETSCH Ltd., Germany) used to measure flour. Flour is packed in a polyethylene bag and stored for 24 hrs at $4^{\circ} \mathrm{C}$ to avoid microbial growth.

Restructured rice was made with independent variables, namely the first of the Water Content $\left(\mathrm{X}_{1}\right)$ with five levels, 35\% (M1), 37.5\% (M2), 40\% (M3), $42.5 \%$ (M4), and $45 \%$ (M5). Then in the second treatment, Temperature $\left(\mathrm{X}_{2}\right)$ with two levels, $100^{\circ} \mathrm{C}(\mathrm{T} 1)$ and $26^{\circ} \mathrm{C}$ (T2).In this study, completely randomized design (CRD) with two factors and three replications has been used. The treatment combination is determined by five levels of water content $\left(\mathrm{X}_{1}\right)$, two levels of temperature $\left(\mathrm{X}_{2}\right)$, and control (Japonica Rice).

\subsection{Research implementation}

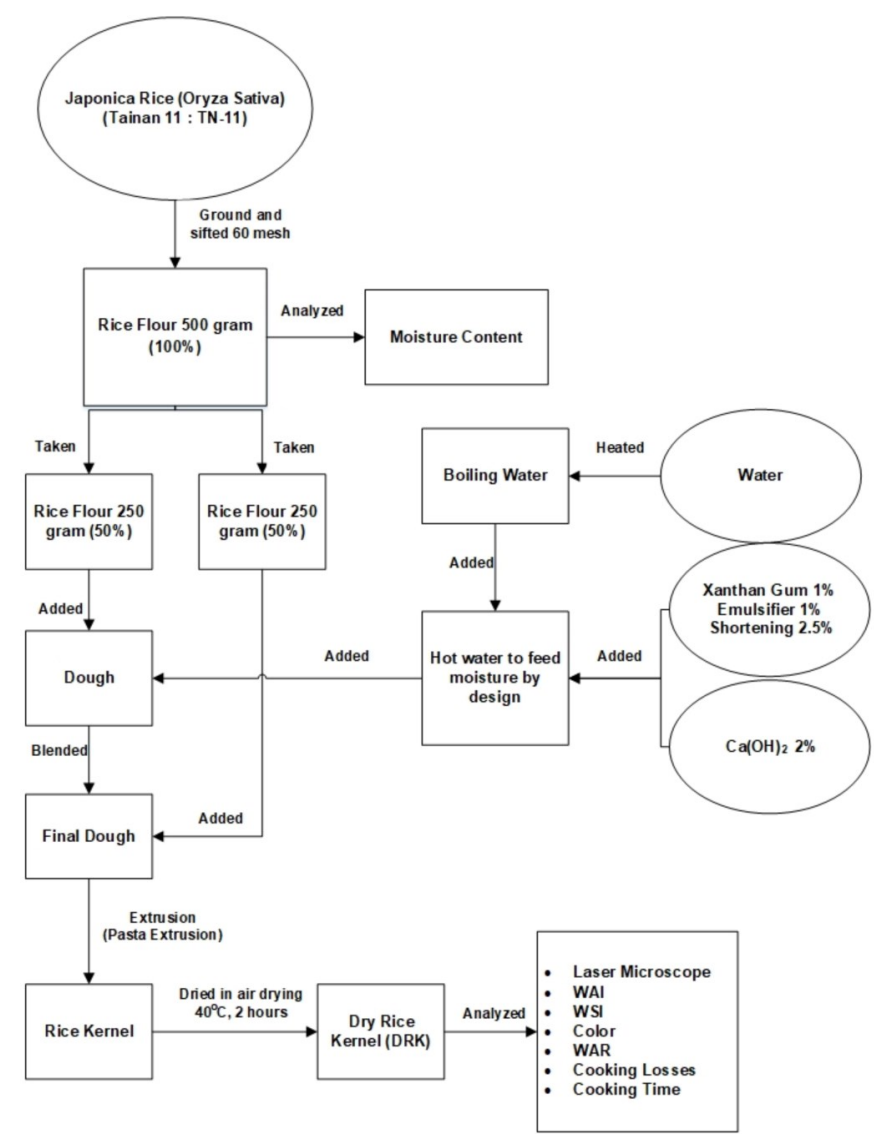

Figure 1. The experimental flow chart in the study

Water is heated using cooking deck (UF-2050, Sony, Japan) at a temperature of $100^{\circ} \mathrm{C}$ and $26^{\circ} \mathrm{C}$ in a beaker glass and closed using aluminum foil and equipped with a thermometer to measure temperature. The water was weighed according to the treatment in the research, namely water contents $35 \%, 37.5 \%, 40 \%, 42.5 \%$, and $45 \%$. Then added with xanthan gum $1 \%(\mathrm{w} / \mathrm{b})$, emulsifier $1 \%(\mathrm{w} / \mathrm{b})$, and shortening $2.5 \%(\mathrm{w} / \mathrm{b})$ in water that has been heated and weighed then stir until evenly. Afterwards, take some rice flour (50\%) and mix with water that has been weighed, heated, added xanthan gum, emulsifier, and shortening. After that blend until homogeneous, then add remaining rice flour $(50 \%)$, and solution $\mathrm{Ca}(\mathrm{OH})_{2} 2 \%$ by $8 \%(\mathrm{w} / \mathrm{b})$ then blend until evenly. Then the dough is placed in Pasta Extruder La Monferrina Model P6 which is shaped like a grain of rice and the dough is cut into fragments. Then, immediately place the restructured rice into the air dryer with a temperature of $40^{\circ} \mathrm{C}$ for 2 hrs. After getting a dry rice 
kernel (DRK), the surface is analyzed by a laser microscope, then analyzed color, water index absorption, and water solubility index. Then, dry rice kernel is cooked to analyze cooking characteristic (water absorption ratio, cooking loss, and cooking time). For more details, the flow chart can be seen in Figure 1.

\subsection{Analysis method}

\subsubsection{Restructured rice surface}

The surface of the restructured rice was observed using a Laser Microscope (VK-X series, Keyence, USA) with 1000x magnification.

\subsubsection{Color analysis}

The restructured rice is ground and then sieved using a 80 mesh. At first, Color Meter (ColorQuest XE, Hunter Lab, Inc., USA) with calibration is prepared, then 50 grams of sample was placed in machine space and then run. The color test is done with color system $\mathrm{L}^{*}$ (Lighting color), a* (red color), and b* (yellow color). A colorimeter is calibrated first with the white standard contained in the tool. The results of the analysis of the resulting white degrees in the form of values $L^{*}, a^{*}, b^{*}$. Measurement of the total degree of color is used as a white base color.

\subsubsection{Water absorption index (WAI) and water solubility index (WSI)}

WAI and WSI are determined using the method by (Dalbhagat and Mishra, 2019). First, the sample flour (2 g) was diluted in $20 \mathrm{~mL}$ of distilled water in $50 \mathrm{~mL}$ centrifuge tubes then mixed for 10 mins and centrifuged at $3000 \mathrm{rpm}$ for 20 mins. After that, the supernatant is placed in an aluminum dish then dried the supernatant in an oven $105^{\circ} \mathrm{C}$ for $24 \mathrm{hrs}$, then the weight of the gel and dried supernatant is recorded. WAI and WSI were determined by the following formula:

$$
\begin{gathered}
\text { WAI }(\mathrm{g} / \mathrm{g})=\frac{\text { Weight of gel }(\mathrm{g})}{\text { Weight of sample }(\mathrm{g})} \\
\text { WSI }(\%)=\frac{\text { Weight of dried supernatant }(\mathrm{g})}{\text { Weight of sample }(\mathrm{g})} \times 100 \%
\end{gathered}
$$

2.4.4 Water absorption ratio (WAR), cooking losses, and cooking time

The ratio of water absorption and loss of solids during cooking is determined using the method by (Singh et al., 2005). Rice samples (5 g) were cooked in $20 \mathrm{~mL}$ boiling distilled water for 10 mins. After cooking is complete, the dissolved solids are moved into an aluminum dish and dried in an oven at $105^{\circ} \mathrm{C}$ for $24 \mathrm{hrs}$. Then the cooked weight is taken and WAR is calculated according to the formula. Dry dissolved solids are weighed, and cooking losses are calculated according to the formula. The cooking time of the sample is determined using the method by (Singh et al., 2005). Rice samples $(5 \mathrm{~g})$ were placed in $20 \mathrm{~mL}$ of boiling water. At 1 minute intervals, ten rice grain samples were taken and pressed between the sliding glass to find out the presence of the white core. The loss of the white core indicates that the rice is ripe. WAR and Cooking Losses were determined by the following formula:

\subsection{Statistical analysis}

$$
\begin{aligned}
& \text { WAR }(\%)=\frac{\text { Weight of cooked rice }- \text { Weight of dry rice }(\mathrm{g})}{\text { Weight of dry rice }(\mathrm{g})} \times 100 \% \\
& \text { Cooking Losses }(\%)=\frac{\text { Weight of dried supernatant }(\mathrm{g})}{\text { Weight of dry rice }(\mathrm{g})} \times 100 \%
\end{aligned}
$$

Data obtained from the study were analyzed by ANOVA using the SPSS Statistic version 22 software. Significantly different data was received by the Duncan's Multiple Range Test (MRT) with a confidence interval of $5 \%$.

\section{Results and discussion}

\subsection{Restructured rice surface}

The surface 3D resulted from the effect of water content and temperature on the restructured rice, which was observed using Laser Microscope, as shown in Figure 2.

Observations using a laser microscope on the surface

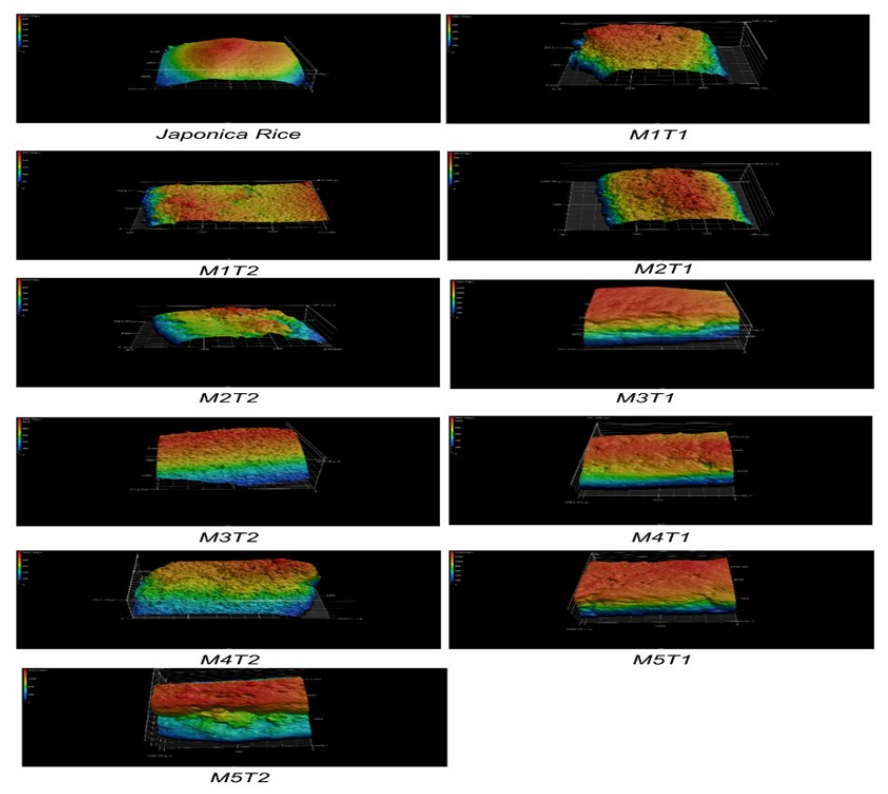

Figure 2. Laser Microscope on the surface of japonica rice (commercial) and restructured rice 1000x magnification.

of the restructured rice that is treated at a moisturized feed temperature of $26^{\circ} \mathrm{C}$ compared with a temperature of $100^{\circ} \mathrm{C}$. The picture shows that the treatment of temperature $26^{\circ} \mathrm{C}$ surface of restructured rice is more porous, so it is broken more easily. This is related to the temperature of starch gelatinization and the effects of the 
gelatinization process in the dough. At $100^{\circ} \mathrm{C}$, the gelatinization process can strengthen the restructured rice granules, and the surface is stronger and smoother. Budi et al. (2013) reported that at extrusion temperatures of $70^{\circ} \mathrm{C}, 80^{\circ} \mathrm{C}$, and $90^{\circ} \mathrm{C}$, the water content of the dough is $35 \%, 40 \%$, and $45 \%$, the extrusion process causes the starch in analog rice to be fully gelatinized (degree of gelatinization 100\%). While at room temperature, starch gelatinization does not occur so that the surface is flat and causes little damage to the surface of the restructured rice. And the more the water content increases, the more the density level of the restructure rice also increases. Similar research has been conducted by Zhuang et al. (2010) that the bulk density of extrudates varies not significantly with temperature changes $30^{\circ} \mathrm{C}$ and $50^{\circ} \mathrm{C}$. It is also evident that the extrudates structure becomes denser due to the feed water content increased from $28 \%$ to $36 \%$. Lower screw extruder speed becomes relatively looser structures are formed in the extrudates. With a higher screw extruder speed, retention time is shortened, and feed gelatinization rate is low, and mixing of dough is not homogeneous exists, so there is a relatively denser structure in it extrudates.

\subsection{Color}

The effect of water content and temperature on the color of the restructured rice can be seen in Figure 3. The result is that the lightness (L) of the restructured rice tends to be lower than milled rice due to the addition of other components such as xanthan gum, emulsifier, and shortening. Temperature tends to affect the red color (a) because there are some component changes during the process of mixing the dough in hot water, such as denaturation of proteins and starch gelatinization.

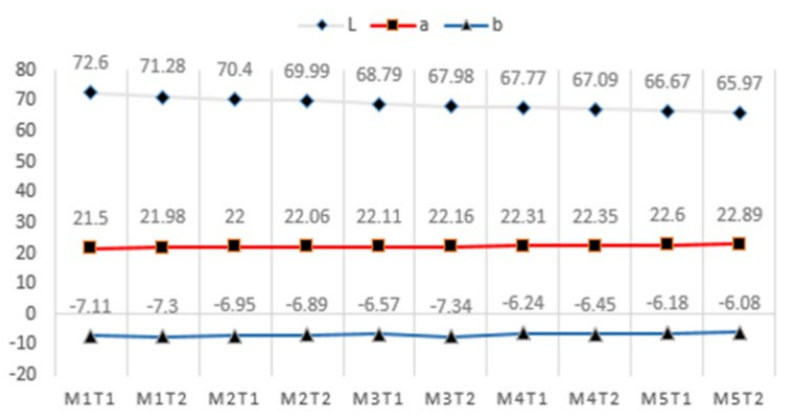

Figure 3. Effect of water content and water temperature on the color of restructured rice.

Temperature and water content do not affect the yellowish color (b). This is because the material used is rice flour does not contain a reducing sugar component so that no Maillard reaction occurs.

\subsection{Physical characteristics}

The effect of water content and temperature on the water absorption index (WAI) and the Water-Soluble Index (WSI) of restructured rice can be seen in Table 1.

\subsubsection{Water absorption index (WAI)}

Table 1 shows the result for the WAI which is not significantly different between control, M1T1, and M1T2. The value for WAI ranges between 1.836 and 2.614. The temperature of water mixed in the dough showed results affect the WAI, the temperature of $100^{\circ} \mathrm{C}$ yield a lower WAI compared to the temperature of water $26^{\circ} \mathrm{C}$. Increased water content results in a higher WAI. Water absorption index (WAI) is the ability of a material to absorb a certain amount of water. WAI can be used as a functional indicator to know the degree of cooking of extruded products. We can notice the increase in the amount of starch gelatinized in the extrusion process. High temperature and pressure will cause more and more starch to undergo dextrinization. Dextrinized starch plays a role in water absorption. This affects WAI which includes several extrusion process input variables, such as extruder type, feed water content, feed rate, screw speed, last barrel temperature, screw configuration, screw compression ratio, and die size. Water is very influential as a plasticizer in the extrusion process, which can reduce the degradation of rice starch and can increase the water absorption capacity of an extrudate (Bryant et al., 2001; Liu et al., 2011). And also, Liu et al. (2011) reported that increased screw speed and moisture could increase WAI in rice. Meanwhile Hagenimana et al. (2006) reported at high temperature and low moisture, WAI decreased significantly due to dextrinization gelatinization in rice analogs.

Table 1. Physicochemical properties of restructured rice

\begin{tabular}{ccc}
\hline & & \\
Sample & $1.836 \pm 0.01^{\mathrm{a}}$ & $0.987 \pm 0.10^{\mathrm{a}}$ \\
& $1.912 \pm 0.05^{\mathrm{ab}}$ & $1.797 \pm 0.23^{\mathrm{bc}}$ \\
& $2.013 \pm 0.04^{\mathrm{abc}}$ & $1.669 \pm 0.28^{\mathrm{b}}$ \\
\hline Control (Japonica Rice) & $2.120 \pm 0.12^{\mathrm{bc}}$ & $1.910 \pm 0.41^{\mathrm{bc}}$ \\
M1T1 & $2.168 \pm 0.11^{\mathrm{bcd}}$ & $1.864 \pm 0.17^{\mathrm{bc}}$ \\
M1T2 & $2.273 \pm 0.10^{\mathrm{cde}}$ & $2.114 \pm 0.11^{\mathrm{bc}}$ \\
M2T1 & $2.392 \pm 0.06^{\mathrm{def}}$ & $1.977 \pm 0.21^{\mathrm{bc}}$ \\
M2T2 & $2.434 \pm 0.02^{\mathrm{def}}$ & $2.204 \pm 0.06^{\mathrm{bc}}$ \\
M3T1 & $2.467 \pm 0.32^{\mathrm{ef}}$ & $2.142 \pm 0.14^{\mathrm{bc}}$ \\
M3T2 & $2.561 \pm 0.04^{\mathrm{f}}$ & $2.279 \pm 0.44^{\mathrm{c}}$ \\
M4T1 & $2.614 \pm 0.03^{\mathrm{f}}$ & $2.187 \pm 0.04^{\mathrm{bc}}$ \\
M4T2 & & \\
M5T1 & & \\
M5T2 & & \\
\hline
\end{tabular}

*Values with different superscript letters within the column are significantly different $(\mathrm{p}<0.05)$ 


\subsubsection{Water solubility index (WSI)}

Table 1 shows the result of the WSI which is significantly different between control and treatments. The value for WAI ranges between 0.987 and 2.279. The temperature of water mixed in the dough showed to affect the WSI, the temperature of $100^{\circ} \mathrm{C}$ yield a high WAI compared to the temperature of water $26^{\circ} \mathrm{C}$, and increased water content results in a higher WSI. The number of water-soluble materials in a certain amount of water. After starch repair, gelatinization will occur the degradation of amylose and amylopectin to produce smaller molecules. This degradation occurs during the extrusion of materials at high temperature and pressure conditions. These relatively small molecules are more easily dissolved in water. Onwulata et al. (2001) reported higher water will cause a higher material flow rate in the barrel to reduce shear and starch degradation whereas Stojceska et al. (2009) reported if lower water was associated with high starch degradation due to high shear. The increase in WSI value is thought to be due to the disintegration of the amylopectin and amylose chains in the extrusion process, thereby increasing the total dissolved solids (Sandrin et al., 2018).

\subsection{Cooking properties}

The effect of water content and temperature on water absorption ratio (WAR), cooking loss, and cooking time of restructured rice can be seen in Table 2 .

\subsubsection{Water absorption ratio (WAR)}

Table 2 shows the result for the WAR which is significantly different between control and treatments, however in treatment M3T1 and M4T2 are not significantly different. The value for WAI ranges between 55.93 and 173.86. Water content and temperature affect WAR value from restructured rice. The temperature of $100^{\circ} \mathrm{C}$ used in the dough produces a lower WAI compared to the temperature of $26^{\circ} \mathrm{C}$.
Increased water content increases in WAI value. The results of this study prove that water penetration into the grains of restructured rice is easier during cooking, due to lower gelatinization temperatures, starch tissue that is weak and porous so that water is more easily absorbed in restructured rice. In a similar experiment by L. Wang et al. (2016) on brown rice pasta which reduces water absorption due to temperature rise, however, it remains the same as the screw speed increases. Da Silva et al. (2016) reported that gelatinization that occurs in starch can inhibit water absorption. And also, Singh et al. (2005) reported that solid and dense structures reduce water absorption from natural rice seeds during the cooking process. Meanwhile, in a study Kaushal et al. (2012) it was found that the capacity of water absorption increases during the cooking process due to the loss of amylose leaching and crystallinity.

\subsubsection{Cooking loss}

Table 2 shows the result for the Cooking loss which is not significantly different between control, M5T1, and M2T2. The value for WAI ranges between 1.59 and 2.55. Water content and temperature affect cooking loss value from restructured rice. The temperature of $100^{\circ} \mathrm{C}$ used in the dough produces a lower cooking loss compared to the temperature of $26^{\circ} \mathrm{C}$. The increase in water content above $40 \%$ resulted in the decrease in the cooking loss value. The amount of cooking loss is influenced by factors such as incomplete starch gelatinization under mild extrusion conditions (eg, lower temperatures with combined effects of water) or excessive starch degradation under severe extrusion conditions (eg, low temperatures in combination with screw speed, water, and feed rate). Besides that, at $40 \%$ water and $100^{\circ} \mathrm{C}$ temperature produce a restructured rice that has a finer surface structure and its porosity is very tight (M3T1 Figure 2). Wang et al. (2016) reported the temperature during the extrusion process and the screw speed can also significantly affect the quality and texture

Table 2. Cooking properties of restructured rice

\begin{tabular}{cccc}
\hline Sample & WAR $(\%)$ & Cooking Losses $(\%)$ & Cooking Time (min) \\
\hline Control (Japonica Rice) & $55.93 \pm 0.19^{\mathrm{a}}$ & $1.59 \pm 0.09^{\mathrm{a}}$ & $10.33 \pm 0.71^{\mathrm{f}}$ \\
M1T1 & $116.30 \pm 0.07^{\mathrm{b}}$ & $2.33 \pm 0.02^{\mathrm{d}}$ & $3 \pm 0.01^{\mathrm{a}}$ \\
M1T2 & $131.03 \pm 0.50^{\mathrm{c}}$ & $2.55 \pm 0.05^{\mathrm{e}}$ & $4 \pm 0.01^{\mathrm{abc}}$ \\
M2T1 & $129.08 \pm 0.22^{\mathrm{d}}$ & $2.03 \pm 0.09^{\mathrm{c}}$ & $3.33 \pm 0.71^{\mathrm{ab}}$ \\
M2T2 & $134.93 \pm 0.15^{\mathrm{e}}$ & $2.24 \pm 0.06^{\mathrm{d}}$ & $4.66 \pm 0.71^{\mathrm{bcd}}$ \\
M3T1 & $150.99 \pm 0.77^{\mathrm{g}}$ & $1.92 \pm 0.10^{\mathrm{c}}$ & $4 \pm 0.01^{\mathrm{abc}}$ \\
M3T2 & $147.61 \pm 0.78^{\mathrm{f}}$ & $2.05 \pm 0.07^{\mathrm{c}}$ & $5 \pm 0.01^{\mathrm{cd}}$ \\
M4T1 & $152.78 \pm 0.12^{\mathrm{h}}$ & $1.75 \pm 0.07^{\mathrm{b}}$ & $4.66 \pm 0.71^{\mathrm{bcd}}$ \\
M4T2 & $150.59 \pm 0.85^{\mathrm{g}}$ & $1.83 \pm 0.03^{\mathrm{b}}$ & $5 \pm 0.01^{\mathrm{de}}$ \\
M5T1 & $162.60 \pm 1.08^{\mathrm{i}}$ & $1.70 \pm 0.01^{\mathrm{ab}}$ & $4.5 \pm 0.71^{\mathrm{de}}$ \\
M5T2 & $173.86 \pm 0.59^{\mathrm{j}}$ & $1.88 \pm 0.01^{\mathrm{ab}}$ & $5 \pm 0.01^{\mathrm{e}}$ \\
\hline
\end{tabular}

*Values with different superscript letters within the column are significantly different $(\mathrm{p}<0.05)$ 
properties of brown rice pasta. The pasta produced using an extrusion temperature of $120^{\circ} \mathrm{C}$ and a screw speed of $120 \mathrm{rpm}$ has the best quality with a cooking loss of 6.7. According to Da Silva et al. (2016) It can be attributed that the role of gelatinized starch can be used as a binding agent in extruded products.

\subsubsection{Cooking time}

Table 2 shows the result for the Cooking time which is significantly different between control and treatments. The effect of water content and temperature on cooking Time of restructured rice can be seen in Table 2. The temperature of $100^{\circ} \mathrm{C}$ and $60^{\circ} \mathrm{C}$ used in the dough has an average cooking time of 3-6 mins on the treatments, while the control has value 10.5 mins. An increase in feed water content increases the cooking time of restructured rice. The higher the water content, the longer it takes to cook. This is because the water absorption into the grains of the restructured rice takes longer due to the dense granules. The higher the temperature in the dough, the cooking process is shorter because the starch gel has occurred before cooking. Saini (2015) reported that the nature of analog rice-forming produces the amount of water absorbed during cooking. Besides, processing parameters such as feed humidity and barrel temperature can indirectly contribute to cooking time.

\section{Conclusion}

Water content and temperature in the restructured rice using pasta extruder affect the surface shape. In the study, the best results were treated with the water content of $40 \%$, and a temperature of $100^{\circ} \mathrm{C}$, pores, and surfaces of restructured rice are almost the same as milled rice. Water absorption index (WAI) value $=2,273 \pm 0.10$, WSI $=2,114 \pm 0.11, \mathrm{WAR}=150.99 \pm 0.77, \mathrm{CL}=1.92 \pm 0.10$ and cooking time 4 mins. Suggestions for this research are for further studies such as fortification with other ingredients using a pasta extruder technology and are expected to be implemented and commercialized.

\section{References}

Alavi, S., Bugusu, B., Cramer, G., Dary, O., Lee, T.-C., Martin, L., McEntire, J. and Wailes, E. (2008). Rice fortification in developing countries: a critical review of the technical and economic feasibility. Institute of Food Technologists. Washington D.C., USA: IFT.

Bryant, R.J., Kadan, R.S., Champagne, E.T., Vinyard, B.T. and Boykin, D. (2001). Functional and digestive characteristics of extruded rice flour. Cereal Chemistry, 78(2), 131-137. https:// doi.org/10.1094/CCHEM.2001.78.2.131
Budi, F.S., Hariyadi, P., Budijanto, S. and Syah, D. (2013). Teknologi Proses Ekstrusi untuk Membuat Beras Analog (Extrusion Process Technology of Analog Rice). Jurnal Pangan, 22(3), 263-274. [In Bahasa Indonesia].

da Silva, E.M.M., Ascheri, J.L.R. and Ascheri, D.P.R. (2016). Quality assessment of gluten-free pasta prepared with a brown rice and corn meal blend via thermoplastic extrusion. LWT-Food Science and Technology, 68, 698-706. https://doi.org/10.1016/ j.lwt.2015.12.067

Dalbhagat, C.G. and Mishra, H.N. (2019). Effects of Extrusion Process Conditions on System Parameters; Physicochemical Properties and Cooking Characteristics of Extruded Fortified Rice Kernels. Journal of Cereal Science, 89, 102782. https:// doi.org/10.1016/j.jcs.2019.05.016

Hagenimana, A., Ding, X. and Fang, T. (2006). Evaluation of rice flour modified by extrusion cooking. Journal of Cereal Science, 43(1), 38-46. https://doi.org/10.1016/j.jcs.2005.09.003

Kaushal, P., Kumar, V. and Sharma, H. (2012). Comparative study of physicochemical, functional, antinutritional and pasting properties of taro (Colocasia esculenta), rice (Oryza sativa) flour, pigeonpea (Cajanus cajan) flour and their blends. LWT-Food Science and Technology, 48(1), 59-68. https://doi.org/10.1016/j.1wt.2012.02.028

Liu, C., Zhang, Y., Liu, W., Wan, J., Wang, W., Wu, L., Zuo, N., Zhou, Y. and Yin, Z. (2011). Preparation, physicochemical and texture properties of texturized rice produce by improved extrusion cooking technology. Journal of Cereal Science, 54(3), 473480. https://doi.org/10.1016/j.jcs.2011.09.001

Mishra, A., Mishra, H.N. and Srinivasa Rao, P. (2012). Preparation of rice analogues using extrusion technology. International Journal of Food Science and Technology, 47(9), 1789-1797.

Mohanty, S. (2013). Trends in global rice consumption. Rice Today, 12(1), 44-45. https://doi.org/10.1111/ j.1365-2621.2012.03035.x

Onwulata, C., Smith, P., Konstance, R. and Holsinger, V. (2001). Incorporation of whey products in extruded corn, potato or rice snacks. Food Research International, 34(8), 679-687. https:// doi.org/10.1016/S0963-9969(01)00088-6

Saini, C. (2015). Preparation of corn flour based extruded product and evaluate its physical characteristics. International Journal of Nutrition and Food Engineering, 9(8), 934-941.

Sandrin, R., Caon, T., Zibetti, A.W. and de Francisco, A. (2018). Effect of extrusion temperature and screw 
speed on properties of oat and rice flour extrudates. Journal of the Science of Food and Agriculture, 98 (9), 3427-3436. https://doi.org/10.1002/jsfa.8855

Singh, N., Kaur, L., Sodhi, N.S. and Sekhon, K.S. (2005). Physicochemical, cooking and textural properties of milled rice from different Indian rice cultivars. Food Chemistry, 89(2), 253-259. https:// doi.org/10.1016/j.foodchem.2004.02.032

Stojceska, V., Ainsworth, P., Plunkett, A. and İbanoğlu, Ş. (2009). The effect of extrusion cooking using different water feed rates on the quality of ready-toeat snacks made from food by-products. Food Chemistry, 114(1), 226-232. https://doi.org/10.1016/ j.foodchem.2008.09.043

Walter, M., Silva, L.P.D. and Emanuelli, T. (2005). Resistant starch: Physico-chemical characteristics, physiological properties and quantification methodologies. Ciência Rural, 35(4), 974-980. https://doi.org/10.1590/S0103-84782005000400041

Wang, J.P., An, H.Z., Jin, Z. Y., Xie, Z.J., Zhuang, H.N. and Kim, J.M. (2013). Emulsifiers and thickeners on extrusion-cooked instant rice product. Journal of Food Science and Technology, 50(4), 655-666. https://doi.org/10.1007/s13197-011-0400-6

Wang, L., Duan, W., Zhou, S., Qian, H., Zhang, H. and Qi, X. (2016). Effects of extrusion conditions on the extrusion responses and the quality of brown rice pasta. Food Chemistry, 204, 320-325. https:// doi.org/10.1016/j.foodchem.2016.02.053

Zhuang, H., An, H., Chen, H., Xie, Z., Zhao, J., Xu, X. and Jin, Z. (2010). Effect of extrusion parameters on physicochemical properties of hybrid indica rice (type 9718) extrudates. Journal of Food Processing and Preservation, 34(6), 1080-1102. https:// doi.org/10.1111/j.1745-4549.2009.00439.x 